\title{
Diretores e gestão democrática: participação da comunidade na escola
}

\author{
Paulo Sérgio Garcia* \\ Valdirene Rodrigues Costa** \\ Marcos Vinicius Zanutto**
}

\begin{abstract}
Resumo
A gestão democrática sinaliza a participação da comunidade na gestão escolar. No entanto, para garantir e intensificar tal participação é importante que o diretor conheça sua comunidade, incluindo o entorno escolar e, neste processo, sua formação é fundamental. Este estudo analisou como diretores estão sendo preparados, na formação inicial e continuada, para lidar com a participação da comunidade na escola, e como eles têm atuado neste cenário. Os dados foram coletados por meio de um estudo de caso, utilizando análise documental e entrevistas. E revelaram que os atuais modelos de formação são, essencialmente, teóricos e têm oferecido pouco espaço para os diretores desenvolverem habilidades para garantir e intensificar a participação da comunidade na escola. Paralelamente, os diretores em serviço apresentaram pouca compreensão sobre as questões da gestão democrática e atuavam baseados em suas experiências cotidianas.
\end{abstract}

Palavras-chave: Diretores; Entorno escolar; Gestão democrática.

\section{Principals and democratic management: community participation in school}

\begin{abstract}
Democratic management indicates the community' participation in school management. However, to ensure and intensify such participation, it is important that the principal knows his community, including the school environment, and in this process, his education is essential. This study looked at how principals are being prepared in initial and continuing education to deal with community participation in school and how they have acted in this scenario. Data were collected through a case study, using documentary analysis and interviews. The data revealed that current educational models are essentially theoretical and have offered little space for principals to develop skills to ensure and enhance community participation in school. At the same time, the principals in service presented little understanding democratic management issues, and worked based on their daily experiences. Keywords: Principals; School environment; Democratic management.
\end{abstract}

\section{Introdução}

A gestão democrática (GD) é intrínseca ao processo de construção e de democratização da sociedade brasileira e, paralelamente, as formas de gerir a escola, considerando os processos de transparência e o estabelecimento da democracia. De forma sintética, ela organiza o funcionamento da escola pública em relação aos componentes administrativos, financeiros, políticos, culturais, sociais, artísticos e pedagógicos, com o objetivo de melhorar a qualidade escolar por meio da participação das pessoas.

Para Cury (2002, p. 173), a GD "é, ao mesmo tempo, transparência e impessoalidade, autonomia e participação, liderança e trabalho coletivo, representatividade e competência". Dourado (2000, p. 79) situou a GD como um processo que inclui aprendizagem e luta política, que não se limita à prática educativa "mas vislumbra, nas especificidades dessa prática social e

\footnotetext{
*Endereço eletrônico: paulo.garcia@uscs.edu.br

***Endereço eletrônico: valdirene.costa@ uscs.edu.br

****Endereço eletrônico: marcosvzatto@hotmail.com
}

de sua relativa autonomia, a criação de canais de efetiva participação e aprendizado do "jogo" democrático e, consequentemente, do repensar das estruturas de poder que permeiam as relações sociais e, no seio dessas, as práticas educativas".

Araújo (2000) apontou a participação, o pluralismo, a autonomia e a transparência como os quatro elementos constitutivos da GD, e sinalizou que o processo de participação inclui vários atores e a comunidade escolar para a construção da autonomia e da democratização da escola. Neste sentido, várias instâncias deliberativas atuam em conjunto. São canais de participação coletivos e de responsabilidade compartilhada: autonomia, seleção de diretores, conselho de classe, conselho de escola, assembleia, grêmio estudantil, financiamento, Projeto Político Pedagógico (PPP) e a participação da comunidade na gestão escolar.

A participação da comunidade na gestão escolar é crucial para romper com concepções e com modelos autoritários, por meio dela busca-se a 
transparência, a autonomia, a representatividade, a cooperação e a competência. Neste sentido, Libâneo (2008) sinalizou que a participação é o meio fundamental para garantir a gestão democrática, pois permite o envolvimento de profissionais e da comunidade na tomada de decisões. Esta integração favorece o conhecimento dos objetivos e dos problemas da escola, entre outros. Lück (2009) relaciona à participação com a questão da responsabilidade social relativa à democracia. A GD, neste caso, procura criar condições para que a comunidade assuma os compromissos necessários para a sua efetivação. Batista (2013) e Bittencourt e Flores (2014) sinalizaram que para a efetiva democratização da escola é necessário mobilizar a participação dos segmentos da comunidade escolar e local.

Neste viés, a participação promove a aproximação entre a escola e a comunidade, auxiliando na redução das desigualdades entre esses atores. No entanto, as oportunidades de participação, em um cenário social, em que as pessoas estão cada vez mais ocupadas e isoladas, dependem da capacidade da gestão escolar em mobilizá-las, e tal mobilização nem sempre tem acontecido, pois os diretores, em geral, não conhecem suas comunidades, incluindo o entorno escolar.

De que forma, então, os diretores podem promover a efetiva participação da comunidade na gestão escolar, como sugerem os autores (LIBÂNEO, 2008; LÜCK, 2009; BATISTA, 2013; BITTENCOURT; FLORES, 2014) se eles não conhecem suas comunidades ou sabem pouco sobre elas? Uma afirmação válida para tal situação é que a participação pode ser garantida e intensificada quando o diretor conhece sua comunidade e o entorno escolar (GARCIA, 2016).

Este último autor realizou indicações para a gestão escolar, diretores e coordenadores, sobre como conhecer a comunidade, explorar e usar o entorno escolar, considerando que a localização da escola pode estabelecer limitações. Mas pode, ao mesmo tempo, também, auxiliar na elaboração e reelaboração do Projeto Político Pedagógico e ampliar os conhecimentos sobre a GD, aproximando a comunidade da gestão escolar, potencializando as aprendizagens das crianças e dos jovens e trazendo informações para os planos de ensino e de aulas dos professores. Esse conjunto de situações intensifica as melhorias na escola. As orientações sugeridas são incluídas em um mapa sobre as questões naturais, estruturais, sociais, econômicas e conjunturais, incluindo as pessoas do entorno escolar.

No entanto, para os diretores conhecerem suas comunidades, investimentos nos processos formativos iniciais e continuados são fundamentais para a formação e a profissionalização do diretor (SANTOS, 2011). Na região do Grande ABC Paulista, uma pesquisa revelou que os alunos do último semestre do curso de pedagogia não se consideravam preparados para gerir as questões da gestão democrática e, em alguns casos, desconheciam totalmente práticas para lidar com a comunidade escolar (OEGABC, 2015). Este estudo situa-se na problemática da gestão democrática com foco na participação da comunidade na gestão escolar. Neste contexto, pretende-se identificar e analisar como os diretores de escola da região do Grande ABC Paulista estão sendo preparados na formação inicial e continuada para lidar com a temática da participação da comunidade na gestão da escola. Paralelamente, investiga-se como esses profissionais têm atuado para garantir a participação da comunidade na escola.

\section{A gestão democrática, a comunidade e o entorno escolar}

A gestão democrática está consolidada nas legislações brasileiras. De acordo com a Constituição Federal, de 1988, artigo 206, ela constitui-se como um dos princípios da educação brasileira. A Lei de Diretrizes e Bases da Educação Nacional (Lei 9.394/96), no artigo 14, também sinalizou, ainda que de forma superficial, a GD, indicando que os sistemas de ensino definirão as normas com base "na participação dos profissionais da educação na elaboração do Projeto Político Pedagógico da escola; na participação das comunidades escolar e local em conselhos escolares ou equivalentes" (Art. 14, LDBEN/1996). Em 2014, o Plano Nacional de Educação (PNE), artigo 2, Lei 13.005, de 25 de junho de 2014, apontou, como orientação para a educação nacional, a gestão democrática. Trata-se da meta 19 do PNE, que visa a assegurar condições para sua efetivação no campo educacional.

A gestão democrática no Brasil aparece como uma possibilidade de reduzir o autoritarismo que reside no processo educativo nas escolas públicas. Propor a GD é conferir autonomia à escola, transparência e participação, por meio de canais de participação coletivos e de responsabilidade compartilhada, tais como: conselho de escola, assembleia geral, grêmio 
estudantil, eleição de diretores, conselho de classe, financiamento, Projeto Político Pedagógico (PPP) e a participação da comunidade na escola.

Em relação à participação da comunidade na GD, Paro (2005, p. 16) sinaliza que "a gestão democrática deve implicar necessariamente a participação da comunidade, parece faltar ainda uma maior precisão do conceito de participação". Para Libâneo (2008), a participação é o principal meio de assegurar a GD, pois cria envolvimento entre a escola e a comunidade e, tal situação, facilita a tomada de decisões. Lück (2009) sinaliza que a participação significa responsabilidade social e a GD pode criar as condições necessárias para a participação da comunidade na escola. Batista (2013) e Bittencourt e Flores (2014) sinalizaram que a escola deveria criar espaços para motivar a participação da comunidade, escolar e local. No entanto, para garantir e intensificar a participação da comunidade na gestão escolar, o diretor deve conhecer sua comunidade, incluindo o entorno escolar, seus limites e suas possibilidades (GARCIA, 2016).

Toda escola tem uma localização que define, em grande medida, suas relações com o entorno escolar, com as pessoas, com os profissionais, com os pais e os alunos e com as situações de aprendizagem. Sua localidade urbana, rural, central, periférica ou em uma área de risco (comunidades carentes) está inserida em um conjunto de símbolos e signos do entorno que estão incorporados na linguagem, compartilhados pelas pessoas e que influenciam, entre outros, o currículo escolar, as aprendizagens e as experiências realizadas. Como já é conhecido, os conhecimentos prévios são fundamentais na construção de novos saberes.

Soares $(2004$, p.86) exemplifica tal situação quando sinalizou que toda escola se localiza em uma comunidade inserida em um espaço social "sobre o qual não tem controle, mas que influencia fortemente as relações estabelecidas nos espaços escolares e, consequentemente, o processo de ensino e de aprendizado".

No cenário brasileiro, no qual crianças e jovens são dirigidos para escolas próximas de suas residências, a localização traduz um tipo de aluno que será atendido. Escolas localizadas em área de risco, atraem, em geral, estudantes com baixo nível socioeconômico e cultural e, neste contexto, geralmente, os pais possuem menor escolaridade.

Soares (2004, p.86) sinalizou que os recursos humanos e materiais das instituições refletem sua localização. Neste caso, escolas localizadas nas áreas de risco ou nas "periferias urbanas e que, portanto, atendem predominantemente alunos de nível socioeconômico mais baixo, apresentam frequentemente piores condições materiais, corpo docente menos qualificado e experiente do que as escolas públicas localizadas na região central das capitais".

Escolas situadas em comunidades carentes, por exemplo, estão mais sujeitas à violência e às situações de tráfico de drogas. Neste contexto, a imagem da escola está fortemente associada ao seu público. A socialização das crianças e dos jovens, neste ambiente, afeta negativamente seus comportamentos e a percepção negativa da comunidade, em que vivem, influencia a escola (BURGOS; PAIVA, 2009). Um cenário em que, segundo os mesmos autores, a percepção dos diretores e dos professores e o projeto escolar entra em choque com o entorno e forma espaços antagônicos em permanente conflito.

Batista et al (2013) revelaram que em escolas localizadas em áreas de alta vulnerabilidade social e com baixo nível socioeconômico, os estudantes apresentavam, em geral, desempenhos menores no Índice de Desenvolvimento da Educação Básica (IDEB), do que aqueles que estudavam em instituições em locais menos vulneráveis.

De fato, a localização da escola pode estabelecer limitações, cujas soluções para superação são complexas. No entanto, conhecer o entorno escolar auxilia a escola, o diretor, trazendo informações para, entre outras coisas, garantir e intensificar a participação da comunidade na gestão escolar.

Neste sentido, para que o diretor conheça sua comunidade e entorno escolar, Garcia (2016) sugere a criação de um mapa, envolvendo questões naturais, estruturais, sociais, econômicas e conjunturais, incluindo as pessoas. $\mathrm{O}$ autor indica (Quadro 1): 
QUADRO 1: síntese de algumas informações requeridas para a elaboração do mapa do entorno escolar

\begin{tabular}{|c|c|}
\hline $\begin{array}{l}\text { Questões } \\
\text { gerais }\end{array}$ & $\begin{array}{l}\text { Tipo clima incidente ao longo do ano (neve); geografia da área (rios ou córregos próximos da instituição, } \\
\text { tipo de ruas); nível socioeconômico do local (média); assistência social; assistência de saúde; segurança na } \\
\text { localidade e na escola (posto policial); incidência de drogas (local de intenso tráfico); visão da comunidade } \\
\text { sobre a escola (positiva); religião preponderante da área (católica, evangélica); origem da escola no bairro } \\
\text { (solicitação da comunidade). }\end{array}$ \\
\hline O lugar & $\begin{array}{l}\text { Conjunto das moradias, edificações, monumentos, parques, rios, fazendas, reservas, supermercados, } \\
\text { oficinas mecânica/pintura, pequenas empresas, prédios públicos, sindicatos, fábricas, shopping center, } \\
\text { prefeitura e secretarias, unidades de saúde, indústrias, bares, associações religiosas, restaurantes, açougues, } \\
\text { departamento de polícia, departamento de água e esgoto, feiras livres, aeroportos, associações de bairros, } \\
\text { universidades, outras escolas, mercadinhos, lojas, cemitério, cinema, museus, zoológico, entre outros. }\end{array}$ \\
\hline $\begin{array}{c}\text { Os } \\
\text { profissionais }\end{array}$ & $\begin{array}{l}\text { Advogados, pintores, pedreiros, serralheiros, aposentados, dentistas, mecânicos, funcionários públicos, } \\
\text { donas de casa, empresários, donos de padaria, engenheiros, médicos, açougueiros, feirantes, professores, } \\
\text { corretores, juízes, fazendeiros, entre outros. }\end{array}$ \\
\hline Os pais & $\begin{array}{l}\text { Nível socioeconômico, formação, origem da família (imigrantes japoneses, italianos...), profissão, tipo de } \\
\text { habitação (casa, apartamento), capital cultural, familiares juntos (pai, mãe e filhos), tipo de valorização da } \\
\text { educação e da escola, grau de atuação com os filhos (cobram postura, viajam juntos, leem, proporcionam } \\
\text { ambiente adequado de estudos em casa, auxiliam nas tarefas de casa), grau de atuação na escola (visitam, } \\
\text { conhecem e conversam com professores e com a gestão escolar), conhecem os amigos, entre outros. }\end{array}$ \\
\hline Os alunos & $\begin{array}{l}\text { Sexo, idade, nível escolar, saúde (alimentação, doença, sono), capital cultural, necessidades, preferências, } \\
\text { motivações, sonho/projeto de vida, medos, fracassos, um pouco da história de vida, envolvimento com } \\
\text { drogas, emoções, efeitos dos pares (grupo na escola), protagonismo juvenil/ capacidades (atleta, músico da } \\
\text { banda escolar), entre outros. }\end{array}$ \\
\hline
\end{tabular}

Fonte: Garcia (2016, p.700-701).

Para o autor, o mapeamento das informações obtidas a partir das questões gerais, do lugar, dos profissionais, dos pais e alunos, possibilita um conhecimento fundamental para auxiliar na elaboração e na reelaboração do PPP e, neste sentido, garantir e intensificar a participação da comunidade na gestão escolar. Ao mesmo tempo, traz informações relevantes que podem auxiliar e potencializar as oportunidades de aprendizagem dos alunos e o desenvolvimento da escola.

As questões gerais trazem informações importantes sobre o entorno escolar: a geografia local, o clima, a saúde, a segurança, a religião das pessoas, dentre outras. No verão, nas regiões Norte e Nordeste, o calor intenso, por exemplo, acrescido à falta de climatização, ausência de ventilação, ventiladores e ar-condicionado nas salas de aula das escolas públicas, gera desconforto e influencia também na aprendizagem da criança e do jovem.

No que se refere ao lugar e aos profissionais que residem no entorno, é possível conhecer, no primeiro caso, como é o local: se há monumentos, parques, supermercados, prédios públicos, shopping center, prefeitura, unidades de saúde e movimentos de bairro; a localização (rua, avenida, praça); meios de transporte (trem, ônibus) e o que estes locais podem oferecer (desenvolver conteúdos de matemática, português, ciências). No segundo, quem são os profissionais que atuam por ali, o que fazem, como podem colaborar (palestra, cursos, serviços), de que forma e em que horário podem participar da gestão da escola, entre outros.

No caso dos pais de alunos, as informações são úteis em dois sentidos: no primeiro, elas contribuem para promover a comunicação e a motivação dessas pessoas para a participação na escola, garantindo a disseminação dos objetivos e das metas, a realização de orientações às famílias em relação aos filhos e, ao mesmo tempo, a verificação do grau de satisfação das mesmas com a escola. No segundo, a questão fundamental é compreender como cada pai ou mãe, individualmente ou em grupo, pode auxiliar a escola. Neste sentido, não faltam exemplos de pais que se mostram dispostos a realizar a pintura da escola, auxiliar na construção de salas de aula ou pintar cadeiras e carteiras. Outros auxiliam na merenda, apoiam ações, participam do reforço 
escolar, ministram palestras e, em alguns casos, colocam pressão nas autoridades locais para melhorias na escola.

Em relação aos alunos, trata-se de conhecer como eles interagem com a comunidade. Alguns, muito possivelmente, são músicos e, outros, praticam esportes, frequentam igrejas ou cultos; alguns, possuem altas habilidades em relação à internet e, outros, se dedicam a coleções. Há aqueles jovens, ainda, que realizam trabalhos voluntários e, outros, que auxiliam os pais no trabalho. Aproveitar essa gama de informações para criar eventos, projetos e iniciativas comunitárias pode aumentar o desejo do aluno em participar da escola (motivação).

Este conhecimento do entorno atrela-se à interlocução entre os atores da escola e o espaço externo. Trata-se de realizar contato, visitar os locais, conhecer as pessoas e os profissionais, convidá-los para visitar e utilizar a escola, concretizar parcerias, vislumbrar e desenhar iniciativas educacionais e projetos educativos e pedagógicos. Um processo de visualização das oportunidades para ampliar a participação da comunidade na escola, mas também, para criar novas oportunidades de aprendizagem para os alunos, dinamizar o trabalho do professor e melhorar a escola. Neste caso, por exemplo, os profissionais podem atuar na realização de palestras, oficinas de aprendizagem, cursos, realizar relatos de experiências, contar histórias, entre outras atividades.

Uma atividade programada para ser realizada, no entorno escolar, pode estar inserida em um projeto colaborativo com um profissional local, com uma loja ou com um supermercado. Tal situação, um evento fora da escola e com caráter mais prático, poderá aumentar o envolvimento, a responsabilidade e a motivação dos alunos em relação à atividade e à aprendizagem. Uma das possibilidades do uso do entorno associa-se à cidadania e à ação social responsável; neste caso, envolvendo alunos e professores em projetos sociais. O ensino, alinhado com a ação social responsável, relaciona-se aos valores e às questões éticas. A educação para a ação social tem o intuito de preparar o cidadão para tomar decisões que sejam conscientes e responsáveis e, ao mesmo tempo, atuar para transformar a sociedade (ZOLLER, 1982; RUBBA, 1991).

Neste processo de conhecimento e aproximação do entorno escolar, o diretor é fundamental. Sua atuação relaciona-se à motivação, à integração e à articulação das diversas tarefas e atividades internas e externas, para viabilizar, entre outras coisas, o planejamento e a tomada de decisões com o intuito de que os objetivos da escola sejam alcançados. Neste caso, quanto maior for essa mobilização, melhor poderá ser o resultado para a participação da comunidade na gestão escolar. Para Fullan (2013), o diretor é um agente de contágio e de mudanças.

No entanto, para os diretores conhecerem suas comunidades, a fim de garantir e intensificar sua participação na gestão escolar, a formação desses profissionais, inicial e a continuada, é fundamental (SANTOS, 2011). Como ressaltou Pereira (2012), ainda há uma ausência de relação entre formação inicial e a gestão escolar democrática.

No mesmo sentido, um estudo realizado pelo Observatório do Grande ABC Paulista (2015), nesta mesma região, mostrou que os alunos no último semestre do curso de pedagogia, futuros diretores, conheciam muito pouco sobre os processos da gestão democrática, não indo além de uma definição rudimentar e do reconhecimento do PPP. Em geral, eles não estavam confiantes com a formação recebida e não se consideravam preparados para enfrentar as questões da gestão democrática, entre outras. Em relação à comunidade escolar, em alguns casos, eles desconheciam totalmente ferramentas e modos de fazer para garantir e intensificar sua participação na gestão escolar.

Além desta questão da formação inicial, Uchoa (2012), em relação à formação continuada, sinalizou que ela atende de forma discreta as necessidades para a promoção de uma organização escolar democrática. No mesmo sentido, uma pesquisa realizada pelo Observatório do Grande ABC Paulista, no ano de 2015, mostrou que esta formação se situa, sobretudo, em aspectos teóricos e que ela não prepara o diretor para lidar com as questões da GD no cotidiano escolar.

Desta forma, o avanço das questões da GD na escola pública, sobretudo para garantir e intensificar a participação da comunidade na gestão escolar, depende da formação e da profissionalização do diretor e, também, de sua equipe.

\section{A Região do Grande ABC Paulista}

O Grande $\mathrm{ABC}$ tem sua localização na região metropolitana de São Paulo, localizada em 
uma área de cerca de $635 \mathrm{~km}^{2}$ e com 2,5 milhões de habitantes (IBGE, 2015). Compõem esta área as cidades de Santo André, São Bernardo do Campo, São Caetano do Sul, Diadema, Mauá, Ribeirão Pires e Rio Grande da Serra.

A renda per-capita da população está assim distribuída: São Caetano possui R \$ 2.349,00, Santo André R\$ 1.499,00, São Bernardo R\$ 1.394,00, Ribeirão Pires R\$ 974,00, Diadema R\$ 917,00, Mauá R\$ 815,00 e Rio Grande R\$ 747,00 (Observatório da Educação do Grande ABC, 2015).

A população da região possui, em média, mais de nove anos de estudo. No entanto, trata-se ainda de uma área com altas desigualdades. Dados do Observatório da Educação do Grande ABC, de 2015, relacionados à desigualdade social (índice Gini), medida que varia entre 0 e 1 ( 0 não desigualdade e 1 maior desigualdade possível), revelaram que as cidades de Santo André $(0,53)$, São Bernardo $(0,54)$, São Caetano $(0,54)$ com maiores rendas, eram aquelas que apresentavam maior desigualdade social (Diadema: 0,43, Mauá: 0,44 e Rio Grande da Serra: 0,39).

O Quadro 2, sintetiza as informações demográficas da região:

QUADRO 2: informações demográficas das cidades do Grande ABC

\begin{tabular}{|c|c|c|c|c|c|c|c|}
\hline Município & $\begin{array}{c}\text { Santo } \\
\text { André }\end{array}$ & $\begin{array}{c}\text { São } \\
\text { Bernardo }\end{array}$ & $\begin{array}{c}\text { São } \\
\text { Caetano }\end{array}$ & Diadema & Mauá & $\begin{array}{c}\text { Ribeirão } \\
\text { Pires }\end{array}$ & Rio Grande \\
\hline $\begin{array}{c}\text { População } \\
\text { estimada 2016 }\end{array}$ & 712.749 & 822.242 & 158.825 & 415.180 & 457.696 & 121.130 & 48.861 \\
\hline População 2010 & 676.407 & 765.463 & 149.263 & 386.089 & 417.064 & 113.068 & 43.974 \\
\hline $\begin{array}{c}\text { Área territorial } \\
\left.\mathbf{( k m}^{2}\right)\end{array}$ & 175,782 & 409,532 & 15,331 & 30,732 & 61,909 & 99,075 & 36,341 \\
\hline $\begin{array}{c}\text { Data de } \\
\text { Fundação }\end{array}$ & $\begin{array}{c}08 \text { de abril } \\
\text { de } 1553\end{array}$ & $\begin{array}{c}08 \text { de abril } \\
1553\end{array}$ & $\begin{array}{c}28 \text { de julho } \\
\text { de } 1877\end{array}$ & $\begin{array}{c}08 \text { de } \\
\text { dezembro de } \\
1958\end{array}$ & $\begin{array}{c}01 \text { de janeiro } \\
\text { de } 1954\end{array}$ & $\begin{array}{c}19 \text { de março } \\
\text { de } 1953\end{array}$ & $\begin{array}{c}26 \text { de maio } \\
\text { de } 1560\end{array}$ \\
\hline IDHM (2010) & $0,815\left(8^{\circ}\right)$ & $\begin{array}{c}0,805 \\
\left(16^{\circ}\right)\end{array}$ & $\begin{array}{c}0,862 \\
\left(1^{\circ}\right)\end{array}$ & $0,757\left(184^{\circ}\right)$ & $0,766\left(134^{\circ}\right)$ & $\begin{array}{c}0,784 \\
\left(58^{\circ}\right)\end{array}$ & $0,749\left(245^{\circ}\right)$ \\
\hline
\end{tabular}

Fonte: IBGE (2016). Elaboração dos autores.

Quanto ao número de escolas e matrículas, os Quadros 3 e 4 sintetizam os dados:

QUADRO 3: Número de escolas do grande ABC - 2015

\begin{tabular}{|c|c|c|c|c|c|c|c|c|c|}
\hline \multicolumn{7}{|c|}{ Número de escolas } & \multicolumn{9}{c|}{ Cidades } & \\
\cline { 3 - 11 } & SA & SBC & SCS & DIA & MAU & RP & RGS & GABC \\
\hline Municipal & E.F. I e II & 50 & 77 & 20 & 28 & 16 & 9 & - & $\mathbf{2 0 0}$ \\
\hline Estadual & E.F. I e II & 86 & 72 & 10 & 56 & 64 & 29 & 11 & $\mathbf{3 2 8}$ \\
\hline
\end{tabular}

Fonte: Censo Escolar (2015). Elaborado pelos autores a partir do Censo Escolar.

São mais de 500 escolas de ensino fundamental na região do Grande $\mathrm{ABC}$ Paulista. O maior número delas está localizado nos municípios de Santo André e São Bernardo do Campo.

O Quadro 04 sintetiza as informações quanto ao número de matrículas:

QUADRO 4: Número de matrículas do grande ABC - 2015

\begin{tabular}{|l|l|l|l|l|l|l|l|l|}
\hline Número de matrículas & \multicolumn{9}{|c|}{ Cidades } \\
\cline { 2 - 7 } & AS & SBC & SCS & DIA & MAU & RP & RGS & GABC \\
\hline
\end{tabular}




\begin{tabular}{|c|c|c|c|c|c|c|c|c|c|}
\hline Municipal & E.F. I e II & 18.070 & 45.538 & 11.211 & 13.122 & 3.030 & 3.330 & 176 & $\mathbf{9 4 . 4 4 7}$ \\
\hline Estadual & E.F. I e II & 37.168 & 31.959 & 2.080 & 34.967 & 40.270 & 8.715 & 4.624 & $\mathbf{1 5 9 . 7 8 3}$ \\
\hline
\end{tabular}

Fonte: Censo Escolar (2015). Elaborado pelos autores a partir do Censo Escolar.

As cidades da região possuíam mais de 90 mil alunos matriculados nas escolas municipais e quase 160 mil nas unidades estaduais. O município com o maior número de matrículas era o de São Bernardo do Campo.

$\mathrm{Na}$ região, o grupo de diretores do ensino fundamental era formado em sua grande maioria por mulheres, tanto na esfera municipal como na estadual, brancas e com idade acima dos 40 anos. Em algumas cidades, neste contexto, mais de $40 \%$ da força de trabalho estava acima dos 50 anos. Essas profissionais foram formadas em Pedagogia, instituições privadas, cursos presenciais e possuíam algum tipo de pós-graduação (especialização 360) horas. Elas tinham experiência na gestão e uma carga horária média de trabalho de 40 horas semanais (GARCIA et al., 2016).

\section{Metodologia}

Este estudo situa-se na problemática da gestão democrática, com o foco na comunidade escolar. Neste contexto, pretende-se identificar e analisar como os diretores de escola da região do Grande do ABC Paulista estão sendo preparados na formação inicial e continuada para lidarem com a temática da participação da comunidade na gestão da escola. Paralelamente, investiga-se como esses profissionais têm atuado para garantir a participação da comunidade na escola.

A região do Grande $A B C$ Paulista foi selecionada, para a presente pesquisa, por ser uma das mais ricas do país, apresentando altos índices socioeconômicos, culturais e educacionais. Os municípios apresentaram, em geral, em 2010, elevados Índices de Desenvolvimento Humano Municipal.

Nesta pesquisa, foi utilizado o estudo de caso na perspectiva de Yin (1993) e André (1984). A coleta de dados foi baseada em análise documental e entrevistas com os diretores das escolas. Foram analisados vários casos simultaneamente, como indicado por Yin (1993), procurando identificar e analisar o fenômeno, revelando a multiplicidade de dimensões presentes. Ao mesmo tempo, não perdendo de vista, como cita André (1984), o foco recaiu na singularidade, que é uma representação única da realidade multidimensional e historicamente situada.

A partir da questão central (como os diretores de escola estão sendo preparados na formação inicial e continuada e como esses profissionais têm atuado para garantir a participação da comunidade na escola), foram: a) analisadas as propostas curriculares e as ementas de três universidades da região do Grande $\mathrm{ABC}$ Paulista, denominadas universidades $\mathrm{A}, \mathrm{B}$ e $\mathrm{C}$, disponíveis em seus sites institucionais. Paralelamente, foram entrevistados os três coordenadores dos cursos de pedagogia dessas instituições; b) entrevistados sete membros das secretarias de educação dos sete municípios, responsáveis pela formação contínua dos diretores, um de cada cidade; c) entrevistados 27 diretores de escolas de ensino fundamental municipais e estaduais. Neste contexto, seis eram de Santo André (três do estado e três do município), seis de São Bernardo (quatro do estado e dois do município), seis de São Caetano (três e três), três de Diadema (dois do estado e um do município), dois de Mauá (um e um), dois e Ribeirão Pires (um e um) e dois de Rio Grande da Serra (estado).

Nos itens b e c, foram coletadas informações sobre o perfil dos participantes em termos de sexo, formação e experiência em educação. No item b, foi investigado quais, que tipo e com que frequência eram realizadas formações em relação à GD, sobretudo, para garantir e intensificar a participação da comunidade na gestão escolar. No item c, foi averiguado: 1) a atuação dos diretores quanto à gestão escolar com a finalidade de garantir e intensificar a participação da comunidade; 2) as dificuldades enfrentadas neste contexto.

A teoria fundamentada, como uma abordagem indutiva de pesquisa, foi usada como suporte para a análise dos dados (CORBIN; STRAUSS, 1998). Dados das entrevistas foram interpretados utilizando uma investigação temática que possibilitou o agrupamento dos temas mais recorrentes, os mais centrais $\mathrm{e}$ os mais significativos, originando as categorias do estudo.

\section{Resultados}

Os resultados apresentados mostram inicialmente como os diretores são preparados, na formação inicial e continuada, para lidar com as 
questões da participação da comunidade na gestão escolar. Por fim, é apresentado como esses profissionais têm lidado, efetivamente, com tais atividades no cotidiano escolar.

\section{A formação inicial dos diretores no contexto da universidade}

As três universidades analisadas, em suas propostas curriculares, possuíam disciplinas que envolviam a questão da participação da comunidade na gestão escolar. Na unidade A, a discussão ocorria na disciplina de "Fundamentos da Gestão Educacional e Coordenação Pedagógica" com carga horária de 80 horas; na $\mathrm{B}$, na matéria de "Gestão escolar", 80 horas, e na $\mathrm{C}$, tal situação ocorria em dois módulos: "Projeto Político Pedagógico e Avaliação: desafios para o sujeito coletivo", com 60 horas e "Planejamento participativo e os processos pedagógicos na escola", com 180 horas.

$\mathrm{Na}$ disciplina de "Planejamento participativo e os processos pedagógicos na escola", da universidade $\mathrm{C}$, por exemplo, previa-se compreender a articulação do contexto sóciohistórico dos estudantes "com os processos pedagógicos da escola, com vistas à formação e participação do sujeito coletivo que pressupõe a intervenção para a transformação social pela via da gestão democrática dos espaços educativos" (EMENTA_UNI_C, 2016).

As ementas das disciplinas forneceram informações que permitiram compreender o conteúdo que era trabalhado com os alunos. Nas três universidades, eram apresentados e discutidos os conceitos da gestão democrática: a seleção de diretores, a elaboração do PPP, a autonomia e a democratização, o financiamento, o conselho de classe, o grêmio estudantil, a assembleia geral da escola, o conselho escolar e a participação da comunidade na escola.

Autores como Jamil Cury, Luiz Fernando Dourado, Regina Vinhaes Gracindo, Ilma Passos Veiga, Vitor Paro e José Carlos Libâneo eram as principais referências analisadas, juntamente com legislações como a Constituição Federal (1988), a Lei de Diretrizes e Bases da Educação Nacional (1996) e o Plano Nacional de Educação (2014).

No entanto, nesta documentação existiam poucas evidências sobre o desenvolvimento de habilidades dos alunos para lidar com a comunidade e o entorno escolar. Não existia em nenhuma proposta pedagógica, das três universidades, uma descrição clara sobre o tema e como atuar ou atrair as pessoas para participar da gestão escolar. $\mathrm{Ou}$ seja, o trabalho era realizado quase que, exclusivamente, de forma teórica.

No intuito de aprofundar as análises, as entrevistas realizadas com os coordenadores dos cursos mostraram pouca diferença sobre o que já havia sido encontrado, ou seja, existe, em cada uma das disciplinas, uma discussão geral sobre a gestão democrática e seus componentes e sobre a participação da comunidade na escola; no entanto, trata-se de uma discussão teórica. Como sinalizou um dos participantes "esta disciplina foca na gestão democrática, pois é importante que o aluno saiba o que é e, também, saiba sua importância para a escola, para o planejamento escolar, mas não dá para ir fundo" (COORDENADOR_UNI_B, 2016).

Quando esses profissionais das três universidades foram indagados sobre como, que ações deveriam ser desenvolvidas para garantir e intensificar a participação da comunidade na gestão escolar, as respostas foram pouco elucidativas, indicando ausência de conhecimento sobre como conhecer a comunidade e o entorno escolar: "esta disciplina não é trabalhada profundamente. Geralmente, os alunos aprendem o que é a gestão democrática e alguns conceitos básicos" (COORDENADOR_UNI_A, 2016), "é uma disciplina teórica onde o aluno tem de aprender mais sobre os conceitos" (COORDENADOR_UNI_C, 2016).

O foco central do trabalho, de acordo com os depoentes, estava assentado na relevância da gestão democrática como princípio orientador da gestão escolar e, ao mesmo tempo, nos aspectos teóricos, sobretudo nos conceitos.

\section{A formação continuada dos diretores no contexto das secretarias de educação}

Os profissionais que participaram desta parte do estudo, aqueles que estavam atuando nas secretarias de educação, eram todos pertencentes ao sexo feminino, com média de idade de, aproximadamente, 48 anos, todos formados em pedagogia e com experiência em educação de, quase, 25 anos.

As entrevistas realizadas com esses profissionais mostraram que o tema gestão democrática estava presente em todos os municípios com preocupações voltadas, sobretudo, para o Projeto Político Pedagógico: "há um trabalho constante para que o diretor elabore seu PPP, use o documento para melhorar a escola e revisite 
sempre o documento junto com os professores. $O$ PPP tem de ser para o diretor uma bússola" (MEMBRO SECRETARIA DE DIADEMA, 2016).

Nos sete municípios ocorreram, nos últimos três anos, reuniões de formação, palestras, cursos e eventos relacionados ao tema gestão democrática. As cidades que mais realizaram tais eventos foram Diadema, Mauá e Santo André e a que menos realizou foi a cidade de São Caetano do Sul.

Nas cidades, segundo os depoentes, os diretores também tiveram algum tipo de formação em relação a garantir e ampliar a participação da comunidade na gestão escolar; ou seja, a realização de atividades que pudessem atrair os pais à participação na escola. No entanto, as entrevistas mostraram que este conhecimento trabalhado aconteceu de forma superficial. Em alguns casos, tratava-se de algumas estratégias ou "truques" para aproximar os pais da escola. Entre essas ações estavam a indicação de agendamento de reuniões periódicas com os pais (para informar os pais, elogiar as crianças, pedir participação); a organização de eventos para a família (exposições, festa junina, feiras do livro); a motivação para o uso de atividades para casa (dever de casa, solicitando o auxílio dos pais com os filhos) para que os familiares adquirissem o hábito de participar da vida escolar do filho; a utilização das redes sociais para a comunicação com as famílias.

Tais indicações, apesar de terem objetivos relacionados à participação da comunidade na escola, eram superficiais, pois os aspetos teóricos predominavam na formação do diretor. Eles não desenvolviam capacidades para conhecer o entorno, os locais, as pessoas e os profissionais, os pais e os alunos. O efetivo conhecimento da comunidade e do entorno escolar, era pouco explorado nos cursos de formação continuada promovidos pelas secretarias de educação e poucos diretores, efetivamente, conheciam e usavam essas informações para planejar com o objetivo de ampliar a participação da comunidade.

\section{O efetivo trabalho dos diretores para garantir e intensificar a participação da comunidade na gestão escolar}

Dos diretores entrevistados (27), a maioria pertencia ao sexo feminino (quase $75 \%$ ), com média de idade de, aproximadamente, 44 anos, todos formados em pedagogia e com experiência em educação de, quase, 15 anos.

Nas entrevistas, os diretores inicialmente situaram que os pais participavam pouco da escola. Alguns desses familiares estavam presentes apenas em reuniões do conselho de escola e outros nos encontros da Associação de Pais e Mestres (APM), indicando fragilidade no processo de participação dos pais na gestão escolar.

As entrevistas revelaram, também, que a gestão democrática já estava bem difundida entre os diretores. Ela já fazia parte do discurso corrente nas escolas, no entanto, havia diferentes entendimentos sobre o seu significado. Alguns diretores tinham uma compreensão mais ampla do conceito se referindo, entre outras coisas, à autonomia da escola, à participação dos pais, ao Projeto Político Pedagógico, à eleição de diretores e à formação do grêmio estudantil. Outros entendiam que a "gestão democrática é fazer o Projeto Político Pedagógico da escola e conversar com os pais" (DIRETOR_SCS_Municipal_02).

Apesar de um discurso já mais consolidado em relação à GD, as evidências coletadas, ao revelarem como os diretores atuavam para garantir a participação da comunidade na gestão escolar, sinalizaram para um quadro de ausência de compreensão sobre a localização e o entorno da escola e sobre a exploração deste espaço.

Tal ausência, sinalizada pelos profissionais, estava atrelada, sobretudo à falta de formação dos diretores e de conhecimentos relativos ao assunto. Nenhum diretor indicou ter apreendido tais conteúdos na formação inicial ou em cursos promovidos pelas secretarias de educação de suas cidades. Sem tal formação, eles atuavam segundo suas percepções do que consideravam importante no cotidiano escolar: "eu faço o que dá pra fazer. A comunidade não participa muito e nós fazemos algumas festas para que eles venham na escola. Nós acabamos decidindo o que fazer para os pais participar, mas não temos orientações sobre isto. Olha na verdade vamos fazendo" (DIRETOR_SCS_Municipal_03).

Neste contexto, vale sinalizar que alguns diretores, nem mesmo, acreditavam que conhecendo a comunidade e o entorno escolar seria possível ampliar as possibilidades de participação dos pais na gestão escolar. Alguns até "zombavam" da questão de ter de conhecer todos os pais, alunos, o local e os profissionais da área. Um diretor sinalizou que "se tiver de fazer isto, conhecer todos os pais e alunos, explorar os arredores da escola, vou fazer só isto o dia inteiro, o ano inteiro e não acho que 
isto vai trazer tantos benefícios assim" (DIRETOR_SCS_Municipal_03).

Alguns diretores apresentaram dificuldades para o conhecimento e o uso do entorno escolar. A principal justificativa foi a questão do tempo. Esses profissionais sinalizaram que na escola as tarefas cotidianas não permitiam assumir outras responsabilidades do que aquelas já incorporadas na rotina escolar.

Outras justificativas foram associadas: à questão financeira, pois atividades fora da escola eram custosas, requeriam dinheiro para ônibus e a escola não dispunha de tais recursos. Para alguns diretores, conhecer e explorar o entorno significaria custos de seu próprio bolso; à segurança, considerando que as saídas da instituição com alunos eram perigosas, mesmo quando existia a autorização dos pais; ao tamanho da escola, pois atividades no entorno quando se possui um número grande de alunos eram impraticáveis e sua realização era muito trabalhosa; à falta de tempo, considerando que as tarefas já eram demasiadamente intensas, restando pouco tempo para investidas não planejadas; aos conteúdos, uma vez que a complexidade desses conhecimentos para serem cumpridos pelos professores dificultava outras tarefas; à falta de autorização, dado que, muitas vezes, a secretaria de educação não permitia saídas externas; à organização da escola, visto que saídas pedagógicas mudavam toda a rotina da escola.

\section{Discussão dos resultados}

A análise das ementas das propostas curriculares das três universidades revelou que elas possuíam disciplinas associadas à preparação do diretor em relação ao tema gestão democrática. As apreciações, ao mesmo tempo, permitiram compreender as referências mais utilizadas e os conteúdos mais abordados pelos professores na formação inicial.

As entrevistas com os coordenadores dos cursos das três universidades reforçaram o entendimento realizado a partir das ementas, segundo o qual a GD e seus componentes (conselho de classe, conselho de escola, assembleia, grêmio estudantil, PPP, comunidade, entre outros) eram discutidos ao longo de um semestre.

Essas análises revelaram que o foco central da formação inicial estava relacionado à demonstração da relevância da GD como princípio orientador da gestão escolar, em um trabalho desenvolvido quase que, prioritariamente, de forma teórica a partir da discussão de conceitos. Ou seja, os cursos e as disciplinas, não ofereceriam ferramentas ou formas preparadas para que os futuros diretores de escola pudessem conhecer suas comunidades, explorar e atuar no entorno escolar de acordo com as indicações realizadas por Garcia (2016), com o intuito de garantir e intensificar a participação da comunidade na gestão escolar. Os dados mostraram que havia, corroborando com os achados de Pereira (2012), uma relação fraca entre formação inicial e a gestão democrática.

Os resultados, deste presente estudo, apontaram na mesma direção da pesquisa realizada pelo Observatório do Grande ABC Paulista (2015), que mostrou que os futuros diretores, já no final da formação, conheciam muito pouco sobre os processos da gestão democrática, não indo além de uma definição rudimentar e do reconhecimento do Projeto Político Pedagógico. Em geral, os alunos, do curso de pedagogia das três instituições analisadas, não estavam confiantes com a formação recebida e não se consideravam preparados para enfrentar as questões da gestão democrática. Em relação à comunidade escolar, em alguns casos, eles desconheciam ferramentas e modos de fazer para garantir e intensificar sua participação na gestão escolar.

As análises da formação continuada desses diretores que atuavam no ensino fundamental mostraram que eram realizados cursos, palestras e eventos relacionados à GD (PPP, trabalho com a comunidade); no entanto, verificou-se que tais incursões eram realizadas de forma superficial, apenas com algumas indicações (agendamento de reuniões periódicas com os pais, organizar eventos para a família, entre outros). Os conhecimentos desta formação não desenvolviam capacidades nos diretores para conhecer suas comunidades e o entorno escolar, como sinalizado por Garcia (2016), garantindo e intensificando a participação da comunidade na gestão escolar. De fato, poucos diretores, efetivamente, conheciam e usavam essas informações para planejar com o objetivo de melhorar as oportunidades de aprendizagens dos alunos e a escola.

Autores que avaliaram programas de formação continuada para gestores (Progestão e Programa Escola de Gestores da Educação Básica), envolvendo a GD, sinalizaram que este tipo de formação atende, apenas parcialmente, às necessidades para a promoção da organização escolar democrática (UCHOA, 2012). Na maioria 
das vezes, eles são teóricos e distante das práticas cotidianas dos diretores.

Por fim, as análises sobre o efetivo trabalho dos diretores em relação à gestão democrática mostraram que os pais participavam pouco e que o tema já estava bem difundido nas escolas, com diversos entendimentos sobre seu significado. Tal difusão, no entanto, estava mais consolidada no discurso entre esses profissionais, do que na concretização das realizações escolares (GARCIA et al., 2016). De fato, a GD ainda está longe de ocorrer da forma em que foi concebida e idealizada pela legislação ou pelas referências de pesquisadores, ou seja, como um instrumento para melhorar a educação brasileira (FERNANDES; PEREIRA, 2016). Autores sinalizam ainda que entre os muitos motivos para que a GD não se efetive estão as estruturas de poder hierárquicas (CAVALCANTI, 2O11; PEREIRA, 2012) e as estruturas e princípios neoliberais (SCALABRIN, 2012).

Em geral, os diretores desconhecem que o conhecimento sobre a comunidade e o entorno escolar possibilita garantir e intensificar tal participação da comunidade na gestão escolar. Tal situação foi creditada à falta de formação tanto inicial como continuada.

Por fim, os dados apontaram algumas justificativas mencionadas pelos diretores quanto às dificuldades para conhecer a comunidade e o entorno escolar. A principal delas foi associada à ausência de tempo. De fato, esse é um desafio que necessita ser considerado e superado para garantir e intensificar a participação da comunidade na gestão escolar, pois o tempo é um dos componentes mais raros nas mudanças (HARGREAVES, 2002). No entanto, é importante situar que dos diretores entrevistados somente dois possuíam um quadro de rotinas semanal de atuação. Ou seja, planejavam as atividades diárias. Para os outros, as necessidades diárias e os imprevistos norteavam as ações a serem realizadas, e tal situação fragiliza as intenções de realizar um trabalho sistemático.

\section{Considerações finais}

Este estudo mostrou como os diretores de escola estavam sendo preparados na formação inicial e continuada para lidar com as questões da participação da comunidade na gestão escolar dentro da proposta de gestão democrática e, ao mesmo tempo, como eles realizavam essas atividades no cotidiano escolar.
Neste contexto, tornou-se visível que as formações inicial e continuada, no cenário do Grande ABC, têm se caracterizado como elementos que contribuem pouco com o ideal e o desenvolvimento da GD, indicando distanciamento da legislação, que sinaliza que a GD deve ser um dos princípios da educação brasileira.

A questão da participação da comunidade na escola é essencial para reduzir as formas autoritárias e lutar por transparência, autonomia, representatividade, cooperação e competência. No entanto, os atuais modelos de formação, inicial e continuada, têm oferecido pouco espaço para o futuro diretor desenvolver habilidades relacionadas à GD, em geral, e a garantir e intensificar a participação da comunidade na escola, em particular.

No caso da formação inicial, toda centralidade dessa em relação à gestão democrática e à preparação dos alunos para lidar com as questões da participação da comunidade na gestão escolar, era desenvolvida quase que exclusivamente de forma teórica. Ou seja, a teoria certificava a relevância dos temas. Uma formação distante da realidade que seria, posteriormente, experenciada pelo diretor no contexto escolar.

A situação da formação continuada, apesar de acontecer com frequência, não ultrapassava a ocorrência de alguns eventos realizados de forma superficial e teóricos, apenas com algumas poucas indicações. De fato, as secretarias de educação dos municípios não tinham políticas claras quanto à formação em gestão democrática e, sobretudo, em como garantir e intensificar a participação da comunidade na gestão escolar.

No contexto da prática diária, os diretores atuavam baseados em suas experiências cotidianas. Alguns realizavam o que consideravam ser mais adequado, sem orientações práticas quanto à gestão democrática e à participação dos pais na escola, enquanto outros apresentavam justificativas como a falta de tempo para a realização do trabalho. Esses profissionais até conheciam a GD e alguns de seus significados, mas muito mais no discurso do que nas ações realizadas no cotidiano escolar. Havia falta de compressão sobre a questão da comunidade e do entorno escolar para garantir e intensificar a participação da comunidade na gestão escolar.

Os dados encontrados neste estudo podem servir de base para discussões na formação inicial, no contexto da universidade, e na formação continuada, no âmbito das secretarias de educação. Eles possibilitam compreender que os processos de 
GD e aproximação dos pais à escola aparecem ainda de forma embrionária no Grande ABC. Ao mesmo tempo, eles permitem a ampliação do debate quanto à gestão democrática, em geral, e à participação da comunidade na escola, em particular.

\section{Referências}

ANDRÉ, M. E. D. A. Estudo de caso: seu potencial em educação. Caderno de Pesquisa, n.54, p.51-54, 1984.

ARAUJO, A. C. Gestão democrática da educação: a posição dos docentes. $2000.220 \mathrm{f}$.

Dissertação (mestrado) - Faculdade de Educação, Universidade de Brasília, Brasília, 2000.

BATISTA, N. C. Políticas públicas para a gestão democrática da educação: um estudo do Programa Nacional de Formação de Conselheiros Municipais de Educação. São Paulo, Jundiaí: Paco Editorial, 2013.

BATISTA, A. A. G. FREDERICA, P.; CARVALHO-SILVA, H. H.; RIBEIRO, L. A. V. A escola e os territórios vulneráveis das grandes cidades. Salto para o Futuro, Brasília, n. 22, p. 1626, nov. 2013.

BITTENCOURT, A. J. A.; FLORES, M. L. R. Desafios para a efetivação de uma experiência de gestão democrática no cotidiano escolar. In: SILVA, M. B. G.; FLORES, M. L. R. Formação à Distância para Gestores da Educação Básica: olhares sobre uma experiência no Rio Grande do Sul. 2014, p. 247-266.

BRASIL. Constituição da República Federativa do Brasil de 1988. Brasília: Presidência da República, Casa Civil, 1988. Disponível em:

<http://www.planalto.gov.br/ccivil_03/Constituicao /Constituiçao.htm> Acesso em: 13 jul. 2015.

Lei $n^{\circ}$ 9.394, de 20 de dezembro de 1996.

Estabelece diretrizes e bases da educação nacional. Diário Oficial [da] República Federativa do Brasil, Brasília, 23 de dez. 1996.

Plano Nacional de Educação, de 25 de junho de 2014. Disponível em: <http://www.planalto.gov.br/ccivil_03/_Ato2011-
2014/2014/Lei/L13005.htm> Acesso em: 23 set. 2016.

BURGOS, M. B.; PAIVA, A. R. (Orgs.). A Escola e a Favela, Rio de Janeiro: PUC-Rio, 2009.

CAVAlCANTI, A. C. D. Programa de Modernização da Gestão Pública / Metas Para A Educação / 2007- 2010: análise sobre a gestão democrática da educação de Pernambuco. 2011. 285 f. Dissertação de Mestrado em Educação. Universidade Federal da Paraíba, 2011.

CORBIN, J.; STRAUSS, A. Basics of qualitative research: techniques and procedures for developing grounded theory. 2 ed. London: Sage Publications, 1998.

CURY, C.R.J. Gestão Democrática da Educação: exigências e desafios. In: Revista Brasileira de Política e Administração da Educação, Porto Alegre: ANPAE, v. 18, n. 2, p. 163-174, jul./dez. 2002.

DOURADO, L. F. A escolha de dirigentes escolares: políticas e gestão da educação no Brasil. In: FERREIRA, Naura Syria Carapeto. Gestão democrática da educação: atuais tendências, novos desafios. 2. ed. São Paulo: Cortez, 2000. p. 77-95.

EMENTA DE CURSO DA UNIVERSIDADE C. Programa de Pedagogia, v. 1, n.1, p. 1-18, 2016.

FERNANDES, S. B.; PEREIRA, S. M. Gestão escolar democrática: desafios e perspectivas. Roteiro, Joaçaba, v. 41, n. 2, p. 451-474, maio/ago. 2016.

FULLAN, M. Stratosphere: Integrating Technology, Pedagogy, and Change Knowledge. Toronto: Pearson. 2013.

GARCIA, P. S. A localização e o entorno da escola. Limitação ou ampliação das oportunidades? Educativa (Goiânia. Online), v. 19, p. 692-708, 2016.

GARCIA, P. S. PREARO, L. C.; ROMERO, M. do C.; BASSI, M. S. Diretores de Escola e Gestão Democrática na Região do ABC Paulista. Política e Gestão Educacional (Online), v. 1, p. 87-107, 2016.

HARGREAVES, A. Aprendendo a mudar. O ensino 
para além dos conteúdos e da padronização.

Primeira edição. Porto Alegre: Artmed, 2002.

INSTITUTO BRASILEIRO DE GEOGRAFIA E

ESTATÍSTICA (IBGE). Disponível em:

https://www.ibge.gov.br/estatisticas-

novoportal/por-cidade-estado-

estatisticas.html? $\mathrm{t}=$ destaques $\& \mathrm{c}=3548807$. Acesso

em: 23 de abril 2015.

INSTITUTO BRASILEIRO DE GEOGRAFIA E

ESTATÍSTICA (IBGE). Disponível em:

https://www.ibge.gov.br/estatisticas-

novoportal/por-cidade-estado-

estatisticas.html? $\mathrm{t}=$ destaques $\& \mathrm{c}=3548807$. Acesso

em: 14 de abril 2016.

LÜCK, H. Dimensões da gestão escolar e suas competências. Primeira edição. Curitiba: Editora Positivo, 2009.

LIBÂNEO, J. C. Organização e gestão da escola: teoria e prática. 5. ed. Goiânia: MF Livros, 2008.

\section{OBSERVATÓRIO DA EDUCAÇÃO DO}

GRANDE ABC (OEGABC). Relatório do primeiro trimestre. Universidade Municipal de São Caetano do Sul. 2015.

PARO, V. Gestão Democrática da Escola Pública. 3.ed. São Paulo, Ática, 2005.

PEREIRA, L. da R. Eleição Direta para Diretor Escolar: desafio à Democratização da Gestão. 2012. 160 f. Dissertação de Mestrado em Educação. Universidade Federal do Pará, 2012.
RUBBA, P. Integration STS into school science and teacher education: beyond awareness. Theory into Practice. United States: Taylor \& Francis, v. 30, n. 4, p. 303-15, 1991.

SANTOS, J. P. S. Atuação dos Conselhos Escolares e a Gestão das Políticas Educacionais: a experiência do município de Alto Alegre do Pindaré-MA. 2011, 155 f. Dissertação de Mestrado em Educação. Universidade Federal do Maranhão, 2011.

SCALABRIN, I. S. Gestão Democrática da Escola Pública: o jogo para além das regras. 2012. $130 \mathrm{f}$. Dissertação de Mestrado em Educação. Universidade de Passo Fundo, 2012.

SOARES, J. F. O efeito da escola no desempenho cognitivo de seus alunos. Revista Electrónica Iberoamericana sobre Calidad, Eficacia y Cambio en Educación (REICE), v. 2, n. 2, 2004.

UCHOA, I. A. T. Política de formação continuada para gestores escolares no estado de Pernambuco: quais as contribuições para a organização escolar democrática? 2012. 117 f. Dissertação de Mestrado em Educação. Universidade Federal de Pernambuco, 2012.

YIN, R. Aplications of case study research. Thousand Oaks: SAGE Publications, 1993.

ZOLLER, U. Decision-making in future science and technology curricula. European Journal of Science Education, v, 4, n. 1, p. 11-7, 1982.

\section{Sobre os autores}

Paulo Sérgio Garcia é pedagogo, Mestre e Doutor em educação pela Faculdade de Educação da Universidade de São Paulo. Possui Pós-Doutorado com a realização de estudos em escolas no Brasil e na Itália. É professor da Universidade Municipal de São Caetano do Sul (Departamento de Educação) e coordenador do Projeto de Observatório da Região do Grande $\mathrm{ABC}$ Paulista, onde desenvolve pesquisas ligadas às escolas, às políticas educacionais e à avaliação educacional.

Valdirene Rodrigues Costa é formada em pedagogia, especialista em Administração escolar e Mestre em Educação pela Universidade Municipal São Caetano do Sul.

Marcos Vinicius Zanutto é formado em Pedagogia, especialista na área de coordenação pedagógica e Mestre em Educação pela Universidade Municipal São Caetano do Sul.

Recebido em novembro de 2016.

Aprovado em outubro de 2017. 